\title{
TRES LIBROS DE BURNS SOBRE JAIME I Y LOS MUSULMANES
}

por

Míkel de EPALZA

El P. Robert Ignatius Burns S. J., profesor de historia medieval en la Universidad de California-Los Ángeles y director del Institute of Medieval Mediterranean Spain, el más importante investigador actual sobre el siglo XIII valenciano, ha publicado recientemente tres libros muy fundamentales para la comprensión de los musulmanes en lo que pasa a ser en ese siglo el Reino cristiano de Valencia: Muslims, Christians, and Jews in the Crusader kingdom of Valencia. Societies in symbiosis (Cambridge University Press, Cambridge, 1984). Society and Documentation in Crusader Valencia (Princeton University Press, Princeton, 1985), Colonialisme medieval. Explotació postcroada de la València islàmica (Eliseu Climent editor, València, 1987). Anteriormente se habían traducido dos de sus libros: Jaime $/ i$ els valencians de/ sigle XIII (Eliseu Climent editor, València, 1981) y El Reino de Valencia en el siglo XIII (Iglesia y Sociedad) (Del Denia al Segura, Valencia, 1982), en espera de nuevas traducciones que hagan más asequible al público culto hispánico, y especialmente valenciano, estos estudios fundamentales para comprender el origen de la sociedad cristiana valenciana y la desaparición de la sociedad islámica precedente.

El último de los libros publicados, Colonialisme medieval. Explotació postcroada de la València islàmica, es el más antiguo de los tres, ya que es la traducción al catalán, revisada, de un libro publicado en inglés en 1975. Se trata del estudio fiscal de los musulmanes bajo poder cristiano en el Reino de Valencia fundado por Jaime I de Aragón. Es una obra fundamental para la fiscalidad y la economía medieval hispánica. Pero es también fundamental para comprender las relaciones económicas de la importante población musulmana («mudéjar») que quedó bajo el poder cristiano. Con el análisis fiscal aparecen muchas de las relaciones engendradas por ese «mudejarismo colonial» que constituye el centro de las investigaciones de Burns, desde su definición acertadísima de la Valencia conquistada como "reino cruzado" y "sociedad colonial» (en sus primeros libros sobre Valencia: The Crusader Kingdom of Valencia: Reconstruction on a Thirteenth-Century Frontier, Cambridge, 
1967, e Islam under the Crusaders: Colonial Survival in the Thirteenth-Century Kingdom of Valencia, Princeton, 1973).

Este libro empieza con un prólogo y un primer capítulo general, que sitúan la problemática fiscal en el marco histórico y social de los territorios valencianos conquistados por la Corona catalano-aragonesa. Estudia la economía "estatal» del nuevo Reino y el peso que tenían los réditos valencianos en el conjunto de los ingresos, peso sin común medida, en tiempo de Jaime I, con los originados por los demás territorios de la Corona. Estudia a continuación las diversas fuentes de ingresos fiscales: tiendas y artesanía, tabernas y carnicerías, hornos de pan y molinos, baños y alhóndigas, los impuestos personales, las tasas viales, las rentas comunitarias y agrarias, impuestos sobre el agua, las obligaciones militares, cargas sobre la sal, la moneda y el ganado, las prestaciones personales, impuestos eclesiásticos y otras cargas diversas. Los capítulos VII, VIII y IX están consagrados al sistema y a los agentes recolectores de estos impuestos, con especial estudio de los agentes judíos de la Corona y las peculiaridades tributarias de los señoríos. Aunque el estudio está centrado en las obligaciones económicas de los musulmanes valencianos, se hacen continuas y muy acertadas referencias a otros sistemas económicos hispánicos y europeos y a la evolución de cada una de las prácticas e instituciones valencianas.

La riqueza de la documentación que aporta Burns sobre los musulmanes valencianos es asombrosa. Como dice en su prólogo, «ilustra la comunidad islámica sometida, capta de mil maneras una visión de la vida a partir de los prosaicos asuntos de dineros". "Los musulmanes valencianos bajo los cristianos no nos han dejado ningún cuerpo de documentación pública, ni memorias o historias, ni códigos de la vida religiosa y social...", pero esta documentación de origen cristiano completa las fuentes de época árabe o las que se pueden sacar de las constantes «islamológicas» de toda sociedad musulmana medieval. Es el gran valor de las fuentes hispánicas, de época mudéjar y morisca, para conocer el mundo musulmán: aportan enfoques que no figuran en la documentación en árabe.

Desde la edición original en inglés de 1975 a la traducción catalana de 1987, el autor ha podido ampliar su obra con añadidos importantes: un prólogo nuevo, un amplio apéndice bibliográfico y algunos párrafos importantes, con nueva documentación. En particular rechaza, por considerarla futil, la polémica que se le ha buscado sobre si pretende insistir sobre la "continuidad" de la sociedad islámica en la sociedad cristiana sin darse cuenta de la uruptura" que se produce con la conquista: él siempre ha defendido que había pervivencia de ciertas realidades islámicas con importantes modificaciones como consecuencia de la irrupción de la nueva sociedad y el nuevo poder político cristiano (lo expuso ampliamente en esta misma revista Sharq Al-Andalus. Estudios Arabes, 1, 15-34). En particular, amplía sus análisis y la documentación sobre el impuesto de la sofra, cuyo origen islámico había puesto en duda Pierre Guichard, y augura nuevos descubrimientos en nuestra línea de investigación (Epalza y Rubiera, Sharq Al-Andalus. Estudios Arabes, 3, 33-37). 
Es de lamentar que el editor de esta traducción, a pesar de su laudable afán de acercar esta obra científica al público hispánico, no haya creído necesario conservar los índices de la edición original, con lo que esta obra pierde gran parte de su utilidad y valor científico. No es el único editor valenciano que se salta asf los índices de obras históricas: la reciente traducción del libro de Lapeyre, importantísima para los moriscos valencianos y su expulsión, ha aparecido también sin índices de nombres de lugar y personas. Nefasta costumbre que no deberia repetirse.

El segundo libro de Burns, Muslims, Christians, and Jews in the crusader kingdom of Valencia. Societies in symbiosis, recoge diez estudios y cuatro apéndices, precedidos de una interesante introducción, que marca el alcance y los límites de estas relaciones inter-religiosas. Estas precisiones de historiador son muy necesarias en el tema: hay una mitificación general de la uconvivencia de las tres religiones" en la Península Ibérica, muy peligrosa para la verdad histórica, que habla más de opresiones religiosas desde el poder que de auténtica tolerancia y respeto hacia las minorías, tanto en la sociedad islámica como en la cristiana. Por eso, las precisiones de Burns son bienvenidas, en tema tan delicado, donde se tiende a tomar los deseos por realidades.

Los diez estudios tienen en común, según su autor, el ser «exploraciones y aventuras" hacia una obra más vertebrada sobre las relaciones islamocristianas en Valencia. Tambien les unen seis características: 1. Se refieren a) mismo reino mediterráneo, uno de los más diversificado, física y étnicamente, de España y quizá de Europa. 2. Se refieren al mismo espacio de tiempo, 1245-1285. 3. Estudian el mismo tema, la ocupación colonial de la sociedad valenciana y la reestructuración simbiótica del reino. 4 . Se basan en la riquísima documentación estatal de Jaume I y Pere III, primer archivo estatal europeo de su época gracias a la abundancia del papel de Xàtiva, en el reino conquistado. 5. Enfocan el mismo tema desde 10 puntos de vista originales. 6. Abarcan niveles de una misma realidad: guerra, lenguaje, religión, ley, literatura, administración, realeza y uraza».

Desde el punto de vista de la Islamología, hay que señalar algunos temas muy originales. Las reflexiones sobre la aculturación en el fenómeno mudéjar. La formación de algunas comunidades o aljamas y su funcionamiento, con todas las lagunas que aún quedan por estudiar en este elemento fundamental para la permanencia del islam durante cuatro siglos en territorio cristiano peninsular. El sueño cristiano de la conversion de los musulmanes. El uso del árabe y de las demás lenguas romances en la Valencia de los mudéjares. El personaje de Al-Azraq y su acción política y militar. La lista de los temas importantes y novedosos de este libro no es en manera alguna exhaustiva.

Una traducción en catalán está preparándose, también por iniciativa del infatigable promotor de la cultura valenciana Eliseu Climent.

Finalmente, el tercer libro, Society and Documentation in Crusader Valencia, es en realidad el primero y la introducción a un proyecto científico fun- 
damental para el conocimiento del nuevo Reino de Valencia, formado por Jaume I el Conquistador: el Diplomatarium del Reino Cruzado de Valencia, las cartas registradas de su conquistador, Jaume I, 1257-1276.

La Corona de Aragón de tiempos de Jaume I comprendía el Reino privativo de Aragón, los condados catalanes origen de la dinastía y unidos ya indefectiblemente a Aragón, al igual que diversos territorios ultrapirenaicos, y los nuevos reinos conquistados a los musulmanes, el insular de Mallorques o $\mathrm{Ba}-$ leares y el de Valencia. Burns estudia el origen y la evolución de la documentación estatal de la Corona y, evidentemente, de la administración que engendra esta documentación. Hay que advertir que es la más importante de todos los estados europeos medievales, con la sola excepción de la documentación pontificia. El que haya sido la primera en guardar sistemáticamente copia de los documentos que enviaba y que haya engendrado una abundantísima riqueza documental se debe sobre todo a la facilidad de tener papel, por haberse posesionado en Valencia con el gran centro papelero que, desde época islámica, era la ciudad de Xàtiva.

No se va a entrar aquí en la importancia de este libro para el estudio de la documentación histórica medieval (diplomática, procedimientos administrativos, descripción material de los documentos, lengua, terminología varia, secciones de los archivos, etc.). Sólo se van a anotar algunos puntos que tocan más directamente a los musulmanes valencianos.

Muy interesante resulta su estudio de los antropónimos, especialmente los de origen árabe y los referentes a castillos (pp. 102-105). También la onomástica de monedas, pesos y medidas. El uso del árabe o de arabismos (pp. 125-133). La revolución papelera que supuso la toma de Xátiva. La simbiosis islamo-cristiana que revela esta documentación (pp. 182-190). El programa de "administración de una frontera" que está en la base del proyecto político de la Corona de Aragón con respecto a Valencia. Los proyectos religiosos del gobierno cristiano. $Y$ muchos otros temas.

En este volumen introductorio lo que se pretende es evidentemente presentar el material disperso que se publicarán en los volúmenes siguientes, los de edición del cartulario. Esos textos, sólo en parte conocidos por anteriores ediciones de Bofarull, Huci, Cabanes y otros, ahora con resúmenes en inglés y numerosas notas identificativas, serán fundamentales para el conocimiento del siglo XIII valenciano.

El equipo de la revista Sharq Al-Andalus. Estudios Arabes, de la Universidad de Alicante, que ha colaborado estos últimos años con las investigaciones del profesor americano y de su equipo (ver volumen 3, pp. 295-296) y va publicando algunos de sus resultados sobre historia árabe bajomedieval, augura nuevos y fecundos volúmenes de investigación del P. Burns. 